\title{
The capabilities and human rights of high performance athletes
}

\section{Abstract}

High performance athletes participate and function in sports systems where exploitative behaviours may become manifest. These behaviours potentially violate an individual athlete's human rights. Using the Capability Approach first outlined by Amartya Sen the paper details how a more precise analysis of human rights, in the context of high performance sport, may be arrived at. Using in-depth narrative accounts from high performance athletes, data illustrate how athlete maltreatment is related to individual capabilities and functionings. The loss of individual freedoms infringes accepted notions of human rights. The implications for practice concern how human rights may be protected within and for systems of high performance production.

Key words: human rights, Capability Approach, athlete, high-performance sport, maltreatment

Word count: 7971 


\section{Introduction}

Is there a problem with the human rights of high performance athletes? Recent cases of abuse have been reported in the media involving coaches and athletes in high performance sport (Roan, 2017, Guardian 2017, BBC 2017a). British cyclist Wendy Houvenaghel, has attributed a 'culture of fear' within British Cycling's world-class programme to UK Sport's 'medals at any cost' 'no compromise' approach (Guardian, 2017). Cycling, rowing, canoeing, gymnastics and English football clubs have each been indicted as having practices that have allowed athletes to have been bullied by over-zealous coaches and managers (BBC, 2017b). Challenging high performance institutions to question the integrity of current practice and consider the duty of care to athletes in performance environments.

The focus of this paper is to introduce the Capability Approach as a normative lens 'for the evaluation of individual well-being and social arrangements' (Robeyns, 2003:5) which we apply to high performance athlete production, the potential for abuse and how human rights may be maintained. We do not set out to interrogate sport systems per se; rather we problematise the human rights of high performance athletes from the evaluative perspective of the Capability Approach. This enables us to ask nuanced questions concerning how high performance athlete production can impact on aspects of individual well-being. The key for Sen appears to be rooted in freedom of choice or genuine choice (Dang, 2014) and underpins considerations of high performance athlete wellbeing within a high performance system. These elements as Sen notes ensure that fidelity to either functionings or capabilities can be approached pragmatically enabling the Capability Approach to focus attention onto 'the constitutive elements of living' (Sen, 1992: 50); in short what it is that enables one to do or to be.

Writers such as Hoch (1972), Meggyesy (2005 [1970]) and Brohm (1987) have each taken a critical lens to interpret the world of sport, and each has found that world wanting with corruption, exploitation and commodification rife in how athletes have been treated and valued by particular sports systems. Both modern sport and human rights have each emerged from periods of barbarism (Brohm, 1987; Edwards, 1969), and Edwards unveiling of the plight of black athletes in 1960s USA, predates this paper in terms of understanding athlete rights amid contexts of free expression and the maintenance of dignity (Edwards 1969). More recently the focus has moved from the sociological to politico-legal frameworks centring on dignity, humanity and recognition. Writers such as Lenskyj (2004), Liu (2007) and Kidd (2010) have each problematised freedom, rights and civil liberties as issues under threat from sport mega events and the 'fuzzy concepts' (Lenskyj 2010; 370) surrounding Olympic Games. Human rights pressure groups such as Amnesty International (2016), 
Human Rights Watch (2012), Centre on Housing Rights and Evictions (2008) and Swedwatch (Jennische, 2014) have also produced critical reports concerning human rights and sport, and bears testament to the increasing salience of sport and human rights to national and supranational governments. There are four globalised aspects observable in this trend. First, the fishbowl of the 'global sporting arms race' (Green and Houlihan, 2005; Grix and Carmichael, 2012); second, epidemiological concerns linking sport to public health promotion (Mann et al 1994, Berg et al 2015, Aggestål and Fahlén 2015). Third, human rights global appeal as a moral and ethical dimension of human interaction; something that governments have, at least rhetorically, sought to promote and fulfil (Doebbler, 2006, Nussbaum, 1997). Fourth, the widespread acceptance of a dominant sport ideology where sport is conceived of as self-evidently a good thing (Rowe, 2005; Coalter, 2007) largely extinguishing dissonant voices (Coakley, 1995; Hartmaan and Kwauk, 2011). Applying the Capability Approach to high performance sport not only serves to highlight the moral and ethical dimensions of a human rights framework and shed light on high performance sport production values across the globe, but also challenges dominant assertions that sport "is the single greatest human rights organisation in the world" (Jennische, 2014: 4).

The Capability Approach in providing the core principles of the Human Development Paradigm (Fukuda-Parr, 2003) enables flexibility in analysing social problems and does not impose rigid orthodoxical policy prescriptions. This flexibility allows the Capability Approach to be applied and have resonance for high performance sport systems because of its applicability to diverse policy questions by moving us on from service provision to political empowerment. In line with the human development approach's emphasis on evaluating success or failure according to the choices or opportunities that individuals have to achieve what they want to do, and hence assessing development by 'how well it expands the capabilities of all people' (Fukuda-Parr, 2003: 304). We argue that the Capability Approach is well placed to allow an analysis and assessment of human rights in high performance sport production by assessing how well high performance athletes' capabilities are nurtured, cared for and expanded. It also normatively facilitates an assessment of obligations and responsibilities, and subsequently contributes to protecting 'vulnerable' populations. The basis for protecting vulnerable populations was the 2001 Report of the International Commission on Intervention and State Sovereignty, which internationalised acceptance of responsibility to protect human rights. The responsibility to Protect $(\mathrm{R} 2 \mathrm{P})$ principle was considered 'path breaking' (Lafont, 2015; 68) and is something that the application of the Capability Approach lens to the context of high performance sport production better illuminates. 
In the following sections, we first examine the Capability Approach as a set of thinking tools that sensitise the reader to the 'language of capabilities' which gives 'important precision and supplementation to the language of rights' (Nussbaum, 2003: 37). Second, we outline the methodology that enabled the collection and interpretation of qualitative data from a study that examined maltreatment of high performance athletes (Kavanagh, 2014). Third, we draw upon data from high performance athlete testimonies to examine the Capability Approachhuman rights nexus in action and in high performance sport. Finally we offer some brief conclusions on the usefulness and application of the Capability Approach for human rights analysis.

\section{The Capability Approach, human rights and the high performance athlete}

Sen's conceptualisation of the Capability Approach is centred on the individual freedoms that allow a person to choose the life, or being that is valued by that individual. The Capability Approach can thus be viewed as a 'moral theory of social arrangements' (Sen, 1985: 37) that rationalises relational and political contexts allowing individual circumstances to be framed within broader political, economic and social contexts (Sen, 1999). It is this normative aspect of the Capability Approach that grounds our examination for the (potential) normalisation of abusive practices in high performance athlete production. It is also noteworthy that the Capability Approach when applied within the high performance sport context allows for a more nuanced examination of how and why a high performance athlete may be in the position that he/she is and whether that position can be objectively viewed for the wellbeing and human rights of that person. As in much of the broader literature on human rights, negative impact is clearer to conceptualise that the positive. For example, an action that potentialises harm is clear. An athlete who is forced to train to breaking point can visibly show how personal freedoms can be infringed and have knock-on consequences for injury, burnout and power and control in the training process. This issue has been conceptualised as forced physical exertion (FPE) and denotes movement from legitimate practice or physical training to abuse (Oliver and Lloyd, 2015; Kerr 2010). The Capability Approach comprises four related aspects; functionings, capabilities, freedom and agency each of which is relevant to human rights as summarised in table 1.

The focus of the Capability Approach pioneered by Sen and developed more recently by Martha Nussbaum, is on people's basic entitlements as expressed in the language of capabilities and human functioning (Nussbaum, 1997). The Capability Approach is an evaluative framework for individual welfare and the social context within which it can be considered. The Capability Approach is derived from Sen's critiques of welfare economics, Rawls Theory of Justice (Sen, 1993; Dang, 2014), and Nussbaum's development of 
Aristotle's consideration of human flourishing and the importance of political organisation in ensuring this (Nussbaum, 1988). We focus mainly on Sen's interpretation of the Capability Approach and his concern for individual wellbeing; in particular what people are able to be and do. We concur that it provides a set of conceptual tools needed to counter perceived intellectual frailties of human rights (Sen, 2005) manifest in the 'mushiness' (Sen, 2004: 315) and fluidity of human rights language (Cmiel, 2004). In placing the Capability Approach and human rights together we are harnessing their 'common motivation' (Sen, 2005: 152) to interrogate high performance sport contexts within the rhetorically thick language of values (Piekarz and Adams, 2015). It is in this respect that this paper is advocatory, promoting contemporary concerns for an inclusive awareness of rights, and how the context of human capabilities in high performance sport can illuminate human rights practice more broadly.

Table 1 about here

\section{The four key elements}

Functionings are 'aspects of living' (Sugden, 1993), states of 'being and doing', what a person manages to do or be (Sen, 1985: 10) amounting to his/her current life condition. They are the result of choices already made and reflect the present condition of an individual's life and can be simple things such as being well-nourished, being healthy, having shelter and for a high performance athlete achievement in their particular sport. In this latter instance it is the realised physical and mental state of an athlete that allows them to do with as he/she pleases; these being the desirable properties of training under their own command (for an educational context see Kelly, 2010).

Capabilities are the available life conditions that enable a possible set of functionings to be available to an individual. They are the ones from which an individual has to choose as well as having the freedom to choose some of them (Jasek-Rysdahl, 2001). Capabilities thus incorporate the idea of freedom, being able to choose between different sets of functionings, and refer to real opportunities to live the life that one has reason to choose and value (Dang, 2014). This arrangement indicates an implicit overlap between capabilities, entitlements and rights such that political liberty is a cherished aspect of much human rights rhetoric and involves freedom to choose different kinds of life. For Sen, capabilities are the 'alternative combinations of functionings that a person can achieve', and from which he or she can choose one collection (1993: 31). Sen later argues that capabilities 'can be seen broadly, as freedoms of particular kinds' (Sen, 2005: 152). One may have the freedom to choose a satisfactory job, satisfactory nourishment or a satisfactory education. This position allows us to consider more clearly the relative freedom of individuals to achieve states of being, for if 
an individual is offered three different university places, then he or she has three different functionings or choices related to university place. The set of three university offers is that person's capabilities set for education, and the one chosen is the realised functioning. Thus having choices and then being able to freely choose from those choices is important for individual wellbeing. Of course there may be barriers that prevent choices being made. For Nussbaum in this respect 'capabilities have a very close relationship to human rights. In effect, they cover the terrain covered by both the so-called "first-generation rights" (political and civil liberties) and the so-called "second-generation rights" (economic and social rights) (Nussbaum, 2003, p.36). The point here is that wellbeing is partly determined by one's ability to make free choices.

Freedom, although a vital component of capabilities, when considered as a separate component of the Capability Approach, has multiple features and underpins human rights insofar as all declarations of human rights concern the ethical affirmation of individuals to be recognised as free human beings (Sen, 2004). This focus on freedom is crucial for both interpreting the relative freedoms of high performance athletes and as an assessment of broader contexts where freedoms may be negotiated. Two important features of freedom are opportunity and process (Sen, 2002). The opportunity aspect concerns the potential for an individual to have access to various combinations of real outputs (functionings) and to choose from them - freedom to choose. When an individual chooses a sports club they do so because it is what they want to do. However there may be barriers; distance and a commute that may preclude particular choices. The consequence is that one's 'process aspect' of freedom is affected by factors involved in the decision making process that although out of one's control are not imposed to prevent a choice being made (Sen, 2002, 2005) - being able to execute that decision.

The final component of the Capability Approach is agency, which for Sen (1985) means one's ability to achieve valued goals regardless of whether those goals are injurious for individual wellbeing. Essentially agency is about choice. An individual's right to choose with the choice they make trumping that of wellbeing. Sen distinguishes between 'agency achievement' and 'agency freedom' in defining what a person is interested in and whether they can fulfil that interest. The former, which Sen confusingly calls 'well-being achievement', amounts to the amount of success in pursuing all of one's goals (Sen, 1985: 51), whilst the latter as 'well-being freedom' encompasses the freedoms one has to realise 'the achievements one values and which one attempts to produce' (Sen, 1992: 57). For Sen the distinctions are necessary in order to provide the precision necessary to explain the outputs of potential action (functionings) from a particular capability set. Furthermore, agency achievement involves goal attainment, but only insofar that Sen views the person as a 'doer 
and judge' (1985: 208); someone with personal responsibility to freely orchestrate the 'achievements one values and which one attempts to produce' (Sen, 1992: 57).

The Capability Approach, human rights and high performance sport contexts

The Capability Approach and human rights are both holistic concepts and bringing them together helps us understand both, as well as allowing appropriate distinctions to be made between a) what a person values doing or being and b) the means that person has to achieve what he/she values (Sen, 2004). In following Sen who allocated more weight to the former, it is possible to develop a more nuanced analysis of the context within which high performance athletes operate and then to evaluate the potential for human rights transgressions to occur. Considering a training squad of high performance athletes; it is likely that each individual will have quite different substantial opportunities in relation to their colleagues each of whom may well have the same set of means (e.g. income). An athlete may be a senior athlete in a squad and be seen as a role model by younger athletes; similarly an athlete may be a breakthrough athlete after posting some exceptional performances. Either way the outcome is a need for 'open valuational scrutiny for making social judgements' (Sen, 2004: 333) and is consistent with the need for public reasoning. In short, those with authority in high performance sport systems should be transparent in assessments and be broadly aware of the capability of the athletes within his/her charge to choose alternative combinations of functionings. Capability in a high performance context is thus about being able to choose (between courses of action) rather than on what is chosen, such that the general idea of freedom does indeed 'figure powerfully in the normative foundations of human rights' (Sen, 2004: 335).

Following on from these concerns about choice, freedom and agency it would be remiss not to observe that Capability Approach operates reflexively within contexts of power that exist in any social situation. Any assessment of high performance athlete practices 'can be sensibly evaluated in the light of their contributions to our freedom' (Sen, 1999: 142), which as Dang notes is 'well-being freedom and agency freedom' (Dang, 2014: 466). High performance athletes must consequently have a real choice; a capability set that enables a range of choices to be made that benefit individual wellbeing, which is freely chosen and not constricted by forces external to the individual. The issue of power is further considered by Sen when he notes that capability and functionings also mark the distinction between social or collective responsibility and individual responsibility. In this respect the circumstances of one's decision making, the opportunities, are beyond the individual and are reliant on constellations of power that construct and normatively condition their operation. As in the example discussed above, a senior high performance athlete is likely to have different 
opportunities to a novice; however each is subject to the normative climate of particular high performance training regimes. Athletes will consequently have varied ideas about well-being, with this variation being extensive dependent on the many factors that influence the "freedom" underlying sport-related choices. These factors may be outside the sport system at the same time that they position athletes differently in the power dynamics that exist in a particular sport system. The training regime itself thus acts on individuals to enable individual capabilities, which are translated via a 'functioning vector within their opportunity set and their choice of the type of life related to it' (Dang, 2014:467). Social justice and/or human rights can therefore be seen to be a matter of capability and the process of converting opportunity to functionings (Sen, 2009).

This brief sketching out of the Capability Approach signals a 'fleshing out' of human rights (Nussbaum, 2011: 62) in creating a nuanced approach to making sense of rights in action, offering 'The most important theoretical development in human rights during the past two decades...(Nussbaum, 2007: 21). We have sought to introduce the Capability Approach for two reasons. First, it is a mediating concept that Sen in particular, uses to temper the tripartite relationship between rights, freedom and obligations; it supports concepts of freedom and the establishment of consequential and contingent obligations. Second, the Capability Approach allows us to characterise particular aspects of systemic processes as 'freedom-restricting' conditions. Athletes who are forced to do something with no freedom of choice are having their process freedom violated. The Capability Approach can thus distil and clarify how individuals, in particular contexts, may have freedoms infringed or abused by the system within which they find themselves.

\section{Methodology}

This paper draws on findings from a broader study of high performance athlete abuse conducted by one of the authors. The research was guided by a qualitative, constructivistinterpretivist approach adopting narrative interviews. Narrative enquiry places a priority upon individual experience through the collection of stories of events and happenings in a participants' life. The storied form allows individuals to recount moments of experience within individual emotional and subjective frameworks and subsequently brings meaning to personal experience (Carless and Douglas, 2013). Adopting a personal experience narrative meant that invited participants were asked to share their personal stories of maltreatment in high performance sport within accounts of personal life stories. Narrative interview questions were adopted as stimuli to provide a trigger for participants to preserve the holistic nature of the story (Jones et al, 2012). Participants were in control of the narrative interviews, with limited interruption from interviewers, ensuring that meaning and understanding of the 
phenomena were described in their own terms, and not directed by the questioning. Interviews examined aspects of sport involvement from participation and progression, to experience of abuse at the high performance level (types, perpetrators and where the experience sat within the individual sporting narrative). The narrative led approach is concomitant with the micro-level analysis needed to highlight the applicability of the capability approach to the human rights of high performance athletes.

In the original sample 12 elite athletes were recruited adopting maximum variation sampling across team and individual sports. Participants had all experienced abuse in their career, were above the age of 18 and had competed at national or international level. The narrative accounts of three participants from this broader study are presented in this paper (two males, one female). These narratives were selected for a number of reasons: First, the participants all participated in team sports, which enabled comparison in relation to funding streams, systems of delivery and the context for abuse to occur. Second, each of the three athletes had been within their respective high-performance system for a full Olympic or World-championship cycle. Third each athlete reported organisational or institutional maltreatment within their narrative accounts and had made attempts to instigate complaint procedures against their respective governing bodies. This comparability was seen as an important factor in the unpacking of the Capability Approach from an interpersonal and organisational perspective within the results and discussion. The research approach prioritised the emic view and took an idiographic approach to data collection (Patton, 2002). Table two provides an introduction to the participants; to ensure confidentiality specific sport references have been removed and participants have been assigned pseudonyms.

Table 2 about here

The narrative interviews lasted between three and five hours in duration; commensurate with the practice of narrative research (Riessman, 2008). Thematic analysis was used to analyse the data, privileging content over the telling of the story (Riessman, 2008). The processes of data collection, analysis and interpretation in this research were not distinct, linear tasks, but were intertwined; an iterative process (Brown \& Potrac, 2009). As Smith and Sparkes (2002) note, the analysis of data relies upon reflection on and interpretation of alternative explanations and interpretations (2002: 266). The analysis of data was both inductive and deductive in nature. The themes emerged inductively from the narrative accounts, with the capabilities approach providing a deductive analytical framework to examine athlete accounts. Three themes are presented: becoming and being an athlete; what it takes, and experiencing maltreatment. The limitations of a sample of three are acknowledged, yet the depth of the narrative turn and the comparability of context are used as a justification here 
for the selection and inclusion of these participant accounts. It is further suggested that the athlete stories have naturalistic generalisability (Stake, 1994) to other sports and settings, and therefore offer an insight into the experience of high performance athletes currently competing in high performance systems.

The following section highlights the lifeworld of each respondent (Van Manen, 1990). This is followed by the thematic discussion that explores athlete testimonies to substantiate our position, which is that when applied to high performance sport contexts the Capability Approach does at least two things. First, it shines a light on the lived experience (Carless and Douglas, 2013) and the social world of the high performance athlete, making the mundane understandable, but not acceptable. Second, it facilitates nuanced and forensic analyses of what human rights are, how they may be transgressed in high performance sport contexts and what an understanding of this may mean for future practice.

\section{Results and discussion}

We present the narrative voices of three high performance athletes using the themes of becoming and being an athlete (journey), what it takes (training, comp, injury (sacrifice) and experiencing maltreatment. These themes emerged from the thematic analysis and by allying the Capability Approach and human rights, allow for precision and clarity in contextualising individual perceived realities, and pragmatically address the very real human rights issues faced by high performance athletes.

\section{Becoming and being an athlete (journey)}

It is easy to think of a high performance athlete as a person who has exercised agency in making freely made key decisions which enable them to do what they want to do. That is attaining the life conditions that allow the individual to be the person (a high performance athlete) they want to be. This would be simplistic and misleading reading of any athlete's journey. High performance athletes are sometimes chosen through particular NGB talent identification pathways; sometimes they develop later in life and come through formal educational routes; sometimes they come through sport specific academies. Commonly, the process of becoming a high performance athlete and developing an individual high performance identity within a particular sport is gradual and self-reinforcing. Understanding the nuances of an athlete's journey can sensitise the reader to interpretations of harm that may be perceived by individual athletes and how choice and freedom are negotiated elements of the Capability Approach and human rights. As an athlete is drawn into the culture of a particular high performance sport, normative processes impact on choice and freedom and subsequently on individual capability and functionings. In this way individual 
functionings may be harmful and deleterious, but this is because capability has been impeded. In a scenario that would appear common to many high performance athletes James explained his journey;

I started when I was 14 through school and then quite quickly got hooked on it. Then when I was 15 I had my first call up to England, so sort of thrown in the deep end quite early on with relatively little experience... When I was 18, 19 I was in the juniors went through a two year cycle with them, and when I was 18 as well I got called up to the Great Britain senior team, I was still a junior but playing with seniors as well. And that was when I started full time training, when I was 18, so it was twice a day from then on in.

It is not uncontroversial to see that James was at this stage living the life that he appears to have chosen and one, which had value for him. It is arguably through this stage that personality development, motivation to succeed and disposition towards living the life of a high performance athlete become embedded. Other systemic factors such as who the coach is, how he/she operates and the extent to which relative freedom for the athlete is both respected and nurtured begin to play out. Ella's story begins at university

I was involved in [names sport] for the first three years of University and competed to the top level... I was a bit frustrated with where I was going. So I thought - that's it I'll go and try something else. A friend of mine was a $X$ [names sport] player at the uni club and said to me "come and have a go we need numbers" ... I played in the varsity match that year and then a year later I got selected for England students which was unexpected... At the end of that season I got called up to go to the Europeans ... then I got a phone call to say that one of the players for England was injured and they needed somebody to go to $X$ (names country) with the full squad to a tournament.

Ella had to make a decision about her future and decided that she needed "to give myself a chance for selection". The decision to commit to World Cup selection meant that she had to make a sacrifice in terms of her career and reduce her working hours in order to concentrate on this goal. She believed that this decision was a necessity, given that other players "within the system" were already full time athletes and supported by higher funding awards. As the above commentary suggests Ella had to make feasible choices that impacted on her functionings and which were derived from the various capability sets available to her. In this instance the athlete is exercising freedom of choice, although already 'sacrifice' suggests a limiting of such choices. Power relations are undoubtedly being seeded here as the athlete acquiesces to prevailing conditions in order that her wellbeing is best served by her making the choices that she does.

As a framework for assessing individual wellbeing and mindful of the human rights application that we contend is useful and appropriate it is clear that individual agency and freedom of a high performance athlete are fundamentally linked to social arrangements and 
how they function. Transposed to high performance sport we can observe the existence of specific sport regimes with particular structural contexts that will have a demonstrative impact on opportunity and process aspect of freedom and well-being freedom and achievement. The Capability Approach suggests that at the moral level we can evaluate structural contexts which impact on an athletes ability to exert agency. Social arrangements thus laid down tend to reinforce the paradoxical nature of some choices made at an early stage of an athlete's career. It is the framing of these sorts of choices as a particular capability set that indicate how human rights maybe infringed as freedoms can get eroded leading to misalignment of functionings to capability. Long term the effect on being able to do the things that a person will value doing (Sen 2005) involving fairness and equity is likely to be negatively impacted.

\section{What it takes}

High performance athletes are understood to be highly driven individuals; performing well and achieving 'medal' status are among some of the prime outcomes linked to their day to day engagement in performance sport. Individual functionings in the form and amount of wellbeing successfully attained is therefore contingent on specific capabilities, freedoms and a capacity to exercise free choice from those that are freely available to that individual. The common use of 'sacrifice' is indicative of a gradual shift from the overt optimism of 'becoming an athlete' to the realism of proving and ensuring one has the capacity for high performance production. Implicit in this expression is a gradual understanding and underscoring of power relations both internally and externally. Internal power relations tend to be signified by an acceptance of discomfort both physically and psychologically, whilst external power relations may encompass the domination of a new regime and or culture that defines individual perceptions within this high performance world. This distinction illustrates the evaluative potential of the Capability Framework to distinguish how power can normatively be interpreted in context and the desirable mental states that relate to considering human rights in situ. For Ella, in the final preparations for a World Cup competition, the difficulty is maintaining the balance between a gruelling work schedule and intensive training. The sacrifice was financial and the choice to put her career on hold in pursuit of a major competition is reflected in the impact on opportunity and process freedom:

"I went part-time at work for the last six months prior to the World Cup which was kind of semi-funded so we got some increased funding... I can't remember what it was, but I know it wasn't enough to kind of compensate for losing half your salary. It was a decision I understood and I made for the right reasons, so I went part time at work, to give myself the best chance." 
In explaining 'what it takes', the adoption of the language of sacrifice and deferred gratification, represents the pragmatic application of a particular capability set from which functionings can be achieved, as demonstrated in the following extract from Adam:

What you find that all throughout this, every little sacrifice you make like going abroad, getting injured and putting up with it, funding yourself, you sacrifice a little and you know, all those little sacrifices build up and up and up. Eventually you've sacrificed a lot... I was paying to play last year, I'm sleeping on the floor this year, I need to get a job now as well... But you keep on going because you're like l've sacrificed this much already... And I'm getting closer to the Olympics, you know that's my goal and now it's so close... If I don't get selected for the Olympics that's the last five years of my life, all that sacrifice is for nothing.

Further down the line of an athlete's participation, James commented about his realised physical and mental state and how his available capability set conditioned functionings

I was ready to walk out of the sport. I was quite happy to move home and just start again; I was not interested in playing for him. It didn't make me want to play for him, if I was on the court I was worried ... I wanted to play well and when I played well it was all fine, but if I made a mistake, even just one mistake in a game, I was worried what the repercussions of that would be in training next week, and I would think about that during games which is not... Now when I think of a game, I'm thinking right, how am I going to win a point, how am I going to beat them, that was how I felt, but that year as I said, he broke me down properly so I was on my heels rather than on my toes. So it was quite tough. There were players that under-performed because they couldn't deal with his pressure. Some players bottled, some players left, I mean some players just said - right, I'm not going to try and make the Olympic squad because I can't deal with that coach.

In this account there is a compromise between individual functionings and wellbeing (utility) to the extent that James's functionings are harmed, and subsequently his human rights are infringed. It is the undesirable properties of the coach, delivered through the system that dominates this interaction. This may be anathema to outsider perceptions of the goldfish bowl of high performance athlete production as a place of privilege, self-fulfilment and meritocratic piety (Shogun, 1999), but indicates a reduction of individual capability to do and be what he/she wants to be. The demarcation is between respect and dignity and conformity and loathing. The functionings that James' valued were unavailable or unobtainable and a denial of opportunity and process freedoms.

It is a truism to state that high performance athletes have a propensity for mental toughness (Mahoney et al, 2014) and to be pushed to their limits (Partington, 2017), however maintaining ethical standards and upholding human rights necessitates not pushing athletes beyond where they might want to be. There is a fine line between being pushed and resisting a forced training exercise designed to enable higher functionings. The issue concerns relative choice and the conditions of enactment and serves to highlight again the usefulness of the Capability Approach in clarifying issues of responsibility, trust and 
accountability. There is a difference between being forced to train to a level that one would have done so anyway as opposed being forced to train to a level that one wouldn't have chosen to do. This primarily impinges on opportunity freedom. Reducing freedom of choice impinges on process freedom (Sen, 2005). Respect of individual's rights to make choices should be paramount. High performance athletes and coaches will each have unique capability sets relevant to particular training regimes, with each having corresponding responsibilities for ensuring that senses of being are maintained. In practice this may amount to coaches/athletes knowing athletes/coaches and treating each other with dignity and respect. It may be possible to speak of a generalised capability set that can apply to a particular set of athletes in a particular sport working with a designated coach or coaching team. In following this position the implicit open-mindedness of the Capability Approach rhetoric as a guide in assessing how well someone might be doing is put to the test. This is important when we consider an athlete's testimony to evaluate relative happiness as an indicator of wellbeing and human fulfilment, and whether individual human rights have been transgressed in any way. It is in this regard that 'adaptive preferences' (Sen, 1990, 1995) the internalisation of particular norms ensuring that individuals do not desire what they cannot be expected to achieve - may have some purchase. This process may have conditioned Ella to make her 'right decision' but can manifest itself in abusive behaviour. Adam recalled how he required a 10-week recovery period for a groin problem incurred through over-training and a failure to appropriately manage acute injuries:

"I went through that ten week period and I missed all of it and obviously you're shitting yourself at that period because actually you've got to remember you're on a performance programme now where you can actually get cut, so the cuts happened every six months... So obviously all the time l'm thinking - crap, if I'm injured for ten weeks that means I'm going to be out because you know you've got to be accelerating and getting better to show that you have what it takes to get to the Olympics,"

The pressure to train and compete is evident at a high performance level and the stress that injury can cause is palpable. Injury will impact on selection, funding and continued participation, which has a consequential impact on particular capability sets and functionings. Thus, what an athlete does or feels able to do is conditioned by his/her context and shows an element of 'adaptive preference'. The long term effects of adaptive preferences for high performance athletes can be catastrophic insofar as an inability to exert agency can lead to harm and an infringement of human rights. The affirmative language of the Capability Approach, which in identifying contextually specific obstacles and by explicating how freedoms may be seen as transient allows for a consideration of how high performance athletes may or may not achieve desired functionings. 
Adaptive preference is useful to signal how capabilities can be interpreted as negative or positive freedom (Sen 1985, 1991, 1992). For human rights this amounts to care of athletes and the culpability of those who are able to exercise power over a particular training situation. Put simply it means that high performance athletes have the right for people to have to exercise responsibility on their behalf. This 'correlate obligation' not only indicates safeguarding and expanding freedoms (Sen, 2005, p.152), but also infers a duty that those in power should act to shape normative processes that condition behaviour within a group. Certainly the moral and evaluative dimensions of the Capability Approach would indicate that those in power hold morally derived obligations for those who they may exert power over (Nussbaum, 2003). This is magnified in professional systemic approaches to performance management, as James was able to comment on;

Sport was my job, my job's target was the Olympics, you know, it's a career then, and while I was playing professionally you know they expect you to perform, they're not paying you to enjoy your sport, they're paying you to play well.

Ella also commented on professionalising and normalising processes that enable a coach to exert power and be controlling as part of a one-sided bargaining process that normatively conditions high performance athletes to perform beyond a moment when it might be safer or more ethical to stop. The accounts suggest that athletes see themselves as pawns in a power game that they are unable to avoid. States of being and doing, expected by an individual in the general populace, may not be available to, or desired by, a high performance athlete. It is this state of affairs that is likely to impact on functionings. Capabilities, concerning choice and opportunity freedom, are subsumed within a controlling structural framework which limits actual choice to that which is most beneficial for high performance sport production. Those who are able to exert power thus have a responsibility to ensure that high performance athlete's freedoms are exerted appropriately with the intention of ensuring that harm is minimised, whether an athlete realises or agrees. The notion of obligations thus has implications for duty of care in high performance sport (GreyThompson, 2017) and implicates many actors from policy makers, to NGBs to individual coaches themselves.

\section{Experiencing maltreatment}

It is useful here to reiterate our advocacy position concerning the promotion of international acceptance of a responsibility to protect human rights. High performance athletes are not a vulnerable population as envisaged by the UN, however as we have argued high performance athletes are increasingly being treated as collateral in the sporting arms race (Oakley and Green, 2001, De Bosscher et al, 2008) and are susceptible to maltreatment 
practices (Stirling, 2013; Stirling and Kerr, 2013). This is largely due to the power of high performance systems to institutionalise and normalise the conditions in which relative freedoms exist and are operationalised (e.g. Pike and Scott, 2015). Freedom (opportunity and process) is an explicit part of wellbeing and human rights (Sen, 2002) and is directly related to opportunities, conversion and achievement. For high performance athletes, freedom concerns having free choice in doing and being;

...you train a certain way for an amount of time, eventually your body adapts so you change it again. When we were doing this it was just, it was a case of mentally and physically adapting to that situation and trying to find the joy in it, you had to find some way of getting through it, and you know it was kind of like... everyone's in the same boat in this ridiculous situation, you've got to find some way of getting through it, for some people in the squad it just broke them... Like properly broke them and you don't get selected in that situation. (Adam)

For Adam the process aspect of freedom (decision making) is forcibly applied even though he may have opted to train in this way anyway. Second, the opportunity aspect of freedom is violated, because options are reduced and then being able to choose freely from those options is denied. In this case being forced to do something that otherwise would not have been chosen. Forced participation and forced physical exertion in activities not only limits choice and contravenes accepted human rights language conventions of the 'right to choose' it can also have deleterious physical consequences as Adam observed;

...you know we were training 25 days solid and I mean solid, by training like that there was a higher risk of injury, there's illness, probably more from being just rundown. There wasn't great co-operation between the medical staff and the coaching staff and instead of the coaching staff and medical staff combining to be 'the staff', we had two very separate identities and no-one was taking control or responsibility for the athletes and that was very fucking dangerous.

Adam further reflected on the concern he felt over a lack of management or regulation of training in the run up to an Olympic games:

...So I knew I had a shoulder problem that was coming on, I knew I had a foot problem that was coming on but I'm six months away, from the games at that point. Do I dare stop - absolutely not, I need to be the best player I can possibly be otherwise I'm going to get there and get killed or I might not get there at all. No one's saying 'let's have a look at your shoulder'. No it's not serious, 'you're OK, you can carry on playing'...there's no-one regulating that and as an athlete you're always pushed further, always pushed further because if you don't you're not really an athlete and the coaches they just keep on pushing... There's no one controlling the way you're developing, you're just literally going one hundred per cent all the time so that can lead to injury.

The apparent forced training to breaking point, of this example, may be something that one would do anyway, and in this case it is different to being forced to do extra sets of exercises, which one may not want to do. This highlights the contrast between the two features of 
freedom as described by Sen. Denials of due process and opportunity as perpetrated by, or on behalf of, would on the face of it be seen as a violation of an individual's human rights. This is even more likely if such choices are not understood and the actions pose a threat to individual wellbeing (Sen, 2005). Furthermore as articulated by James, force and violation were part and parcel of normalised training practice:

You know of course we were worried about injury. If you're jumping 100, 200 times a session your legs are bad, so [are] your knees, your ankles, your hips, your back, it's almost like through that summer the sessions got tough and it was like he [the coach] didn't want to make a decision so he wanted to break you and that would make his decision easier.

The athlete testimonies also indicate that the conditioning towards adaptive preference, to act in accordance with the dominant normative mores of a high performance culture, reflect those of 'an authority' implicating the compromise of opportunities to think and act freely. It is in these contexts that unquestioning acceptance of structure was the dominant mode of engagement. For Ella rocking the boat was certainly not an option;

... when we did take things further they all just went to ground, disappeared and that was every senior player really in the squad who had stood up and said 'we think we're going the wrong way', it just got brushed under the carpet. So even when you do raise or escalate issues you feel like they're easy to shut down, so you know, I think that was the biggest sign of 'we can only say' and then if you're not going to listen to what you're players are saying ... I don't know what more we can say

Similarly for Adam, the threat of Olympic deselection was used to dominate social relations and to create a normalisd compliancy that illustrates how relational and poltical contexts can subtly be used to create fear. Here a form of negative freedom ensures that structural rather than athlete wellbeing is privileged;

We weren't allowed to speak about this because of bringing the sport into disrepute. It got to the point where the guys went 'let's go to the press'. It's a month before the Olympic Games, we've got all this information now about how shit the process has been and we're going to go to the press and say look this is what's happened, this is ridiculous'. Kick mud in UK Sport's face a bit I guess. And [the captain] kind of lost his nerve on it, he had been sort of whittled down and beaten down by [the coach] and all his shit by [the performance director] ... and it was just too much and it kind of broke him a little bit, like he wasn't the leader that he used to be and he just kind of wanted get to the games and get it done. So we sent a letter off to the board and all this sort of stuff saying how we had a vote of no confidence in the organisation, and then it was like 'well let's go to the media'. It's such a shame because $X$ (the performance director) then sent out an email saying if you go to the press we can deselect you from the Olympic squad on the grounds of bringing the sport in disrepute'. So everyone immediately went 'OK and stepped down from it and it went no further."

The athlete testimonies identify the hampering and diminishment of individual responsibility by the dominant social relations embedded in particular high performance sport cultures. 
The collective responsibility to protect individual human rights is either being ignored or sidelined. Here the Capability Approach is able to clarify and crystallise that the circumstances of individual athlete decision making are beyond the competence of any one individual athlete who is embedded within a particular high performance training culture. There may be examples where power shifts empower athletes to enact change; such as in cases of player power or where a paradigm shift occurs due to a significant event. Mediated examples of bullying within high performance regimes, for example, may give rise for a call to policymakers that something must be done. The cases mentioned at the start of this paper are indicative of this scenario. The reliance for appropriate decision making to enable individual capabilities and reduce potential harm for individuals is with those who have the power to do so. This is visible in James' comments about being 'pushed' by a coach. Although James is complicit in the decision making, his individual responsibility is conditioned by the coach(es) who contribute to the capability set from which James chooses and can achieve his functionings;

One would be physically pushing you, some of the drills were physically tough, designed to drain you like a Bleep Test, and you know if he wasn't happy you'd know because he'd make you do something stupid and embarrass you in front of the rest of the team, or try to embarrass you

Looking back you think what an idiot, some of us could have got injured, but at the time you know....male ego sort of thing, we go for it, we push ourselves because.....pride, you don't want to sort of see he beats you. Other times he'd just literally tell us that we were crap and say - right, you're not good and this is not......and we'd gone from sort of the best in our juniors and competing well, to not being able to beat teams in the league.

The analytical themes of becoming an athlete, having what it takes and experiencing maltreatment have shown athlete testimonies to become increasingly darker about their journeys in and through high performance sport. This culminated for James in his observations about athlete colleagues who were physically compromised by seemingly dominant 'at all costs' attitudes

One of the guys, a Scottish lad got an injury in his leg because he did too much jumping, so he took time off - said alright you've got three weeks off, sort yourself out, week and a half, the coach needed him back on the court, He said - 'can't, you know, I've got to have three weeks rest' - 'oh, come on, you'll be alright'. Killed him in the session, killed everybody in that session, but killed him. 'Can't', he said 'I can't play tomorrow, I just can't do it' and he went to the hospital and they said look if you keep playing you're at risk of not walking again. He had some sort of compartment syndrome in his legs, and that was how serious it was.

The value of the Capability Approach is in the nuances of language that enable a closer and more precise analysis of what a person values doing or being and the means that that person has to achieve what he/she values (Sen, 2004). Applied to human rights the 
'common motivation' (Sen, 2005: 152) of the Capability Approach is bound up in a value laden framework where context and relative freedoms can holistically be examined together. The narratives above suggest a progressive movement from optimism to pessimism and correlates with the gradual erosion of freedoms. It is at this micro-level where human rights abuses can be detected first and if left unchecked can lead to compromise and unchecked abusive behaviour and clear abuses of an individual's human rights.

\section{Conclusion}

The preceding analysis highlights how Sen's framework enables a more nuanced inspection of the context within which high performance athletes operate and consequently to evaluate the potential for human rights transgressions to occur. Within a high performance training squad each individual is likely to have quite different substantial opportunities in relation to their colleagues. The capability approach as a holistic framework can usefully sit alongside human rights and can provide authority agents within high performance sport some transparency in assessing and being aware of what, when, where and why high performance athletes may choose alternative combinations of functionings. The Capability Approach thus focuses attention onto the capacity an individual might have to choose (between courses of action) rather than on what is chosen. This signals a 'fleshing out' of human rights (Nussbaum, 2011: 62), creating a nuanced approach that underscores rights in action.

The Capability Approach as evidenced in this paper is also well placed to offer insights about the validity and value of considering choice and liberty as the central foci for evaluating human rights. We are clear that both the Capability Approach and human rights are holistic frameworks, with the Capability Approach centred on the interrelationship between capabilities and functionings. Meaningful freedoms, choice, agency and dignity thus become buttressing concepts providing a more nuanced interpretation of individual rights claims. The accounts of high performance athletes indicate how, when and why, human rights may be damaged, contravened and sublimated through systemic processes. Previous works (for example, Donnelly, 2008; Kidd and Donnelly 2000; Giulianotti, 2004) have tended to take an overview of sport operating within human rights frameworks at a global level, highlighting the basic premise of human rights without investigating or analysing how ethical and moral frameworks may be applied or enacted within and against the systematic production of high performance athletes. We do not consider this paper as beyond reproach in terms of how we conceptualise human rights and high performance athletes. However this paper has clarified the complementary and overlapping elements identified in the Capability Approach, which when applied to high performance athlete contexts, enable the language of capabilities to 
inform a more nuanced understanding of how rights can form and how they might be violated within a particular normative system. We have also shed some light on how obligations form and may be responsibilised within high performance production processes. One does not and should not have to sacrifice the right to have the basic human right of freedom abused or curtailed for the sake of high performance sport.

Understanding the Capability Approach in a high performance context facilitates the establishment of an ethical and moral position from which it is reasonable to argue that high performance sport should be examined to reveal how particular capability sets are established, and how likely athletes are to be able to realise these as functionings. At the policy and pragmatic level this analysis indicates that it is imperative for authority agents to consider how maltreatment of high performance athletes can be avoided. The Capability Approach would suggest it is at the structural level where systemic approaches have initial purchase for the initial protection of athlete human rights. In the UK, the Duty of Care in sport review: Independent report to government (Grey-Thompson, 2017) has proposed the establishment of a sports ombudsman, whilst globally the World Players Association has proposed a Universal Declaration of Player Rights (2017). Each of these initiatives suggests that freedom, respect and dignity as good practice for the development of athletes' human rights are necessary. We have argued that the Capability Approach is a nuanced tool that policy makers and practitioners can use as check and balance for the development of the good practice needed in the context of R2P (Lafont, 2015) and subsequently human rights. 
References

Aggestål, A, and Fahlén, J. (2015) Managing sport for public health: Approaching contemporary problems with traditional solutions, Social Inclusion, 3(3): 108-117

Amnesty International, (2016) The ugly side of the beautiful game. Exploitation of migrant workers on a Qatar 2022 world cup site, London, Amnesty International Ltd

BBC. (2017a) UK Athletics: Ed warner says 'too much' focus on winning medals, London, BBC available at www.bbc.co.uk/sport/olympics/39453640

BBC (2017b) GB canoeing coach suspended after welfare complaint, London, BBC, available at www.bbc.co.uk/sport/canoeing/39450595

Berg, BK, Warner, S, and Bhiba, MD. (2015) What about sport? A public health perspective on leisure-time physical activity. Sport Management Review, 18(1): 20-31

Brohm, JM (1987) Sport: A Prison of Measured Time, London, Pluto Press,

Brown, G, and Potrac, P. (2009). 'You've not made the grade, son': De-selection and identity disruption in elite level youth football. Soccer \& Society, 10(2): 143-59

Careless, D. \& Douglas, K (2013) "In the boat" but "selling myself short": Stories, narratives, and identity development in elite sport. The Sport Psychologist, 27, 27-39.

Centre on Housing Rights and Evictions (2008). One world, whose dream? Housing rights violations and the Beijing Olympic Games, Geneva, COHRE

Cmiel, K (2004) The recent history of human rights, The American Historical Review, 109(1): 117-135.

Coakley, J (1995) Ethics, deviance and sports: A critical look at crucial issues. In: A. Tomlinson \& S. Fleming (Eds.), Ethics, Sport and Leisure - Crisis and Critiques (pp. 3-24). Oxford: Meyer and Meyer Sport.

Coalter, F (2007) Sport a wider social role: who's keeping the score. London, Routledge

Dang, AT (2014) Amartya sen's capability approach: A framework for well-being evaluation and Policy Analysis? Review of Social Economy, 72(4), 460-484

De Bosscher, V, Bingham, J, Shibli, S, van Bottenburg, M, and De Knop, P. (2008). A global sporting arms race: An international comparative study on sports policy factors leading to international sporting success. Aachen, Germany: Meyer \& Meyer.

Doebbler, C. (2006) Introduction to International Human Rights Law, Washington DC, CD Publishing

Donnelly, P (2008). Sport and human rights, Sport and Society, 11(4): 381-394.

Edwards, H (1969) The Revolt of the black athlete, Pennsylvania State University, Free Press

Fukuda-Parr (2003) The Human Development Paradigm: operationalizing Sen's Ideas On Capabilities, Feminist Economics, 9(2-3); 301-317

Giulianotti, R (2004) Human rights, globalisation and sentimental education: The case of sport, Sport in society 7(3): 355-369 
Green, M, and Houlihan, B. (2005) Elite sport development: Policy learning and political priorities, London, Routledge.

Grey-Thompson, T (2017) Duty of Care in Sport: Independent Report to Government, London, HMSO

Grix, J, and Carmichael, F (2012) Why do governments invest in elite sport? A polemic. International Journal of sport policy and politics, 4(1): 73-90.

Guardian (2017) Wendy Houvenaghel says British Cycling medal drive led to culture of fear, London, Guardian Newspaper available at www.theguardian.com/sport/2017/mar/23/wendyhouvenaghel-medal-drive-british-cycling-culture-of-fear

Hartmaan, D and Kwauk, C. (2011) Sport and development: An overview, critique and reconstruction. Journal of Sport and Social Issues, 35(3), 284-305

Hoch, P (1974) Rip off the big game: The Exploitation of Sports by the Power Elite, New York, Doubleday-Anchor

Human Rights Watch (2012) "Steps of the Devil". Denial of women and girls' right to sport in Saudi Arabia, Human Rights Watch, USA

Jasek-Rysdahl, J (2001) Applying Sen's capabilities framework to neighbourhoods: Using local asset maps to deepen our understanding of well-being, Review of Social Economy, 59(3): 313-329

Jennische, H (2014) The Olympic Violations: The Winter Olympic Games in Sochi, the Swedish sponsors and human rights, Swedwatch.

Jones, I., Brown, L. and Holloway, I. (2012). Qualitative research in sport and physical activity. London: SAGE.

Kavanagh, EJ. (2014) The dark side of sport: athlete narratives of maltreatment in high performance environments. Thesis, (unpublished PhD). Bournemouth University, UK.

Kelly, A (2010) School choice policy in England: An adaptation of Sen's early work on capability, Journal of School Choice, 4(3): 317-335

Kerr, G. (2010) Physical and emotional abuse of elite child athletes: the case of forced physical exertion. In Brackenridge $\mathrm{C}, \mathrm{H}$ and D. Rhind (Eds.), Elite Child Athlete Welfare: International Perspectives (pp. 41-50). West London: Brunel University Press.

Kidd, B (2010) Human rights and the Olympic Movement after Beijing, Sport in Society, 13(5): 901-910

Kidd, B and Donnelly, P. (2000) Human rights in sports. International Review for the Sociology of Sport 35(2): 131-148.

Lafont, C (2015) Human rights, sovereignty and the responsibility to protect, Constellations, 22(1):

Lenskyj, H, J (2004) The Olympic Industry and civil liberties: The threat to free speech and freedom of assembly, Sport in Society, 7(3): 370-384

Liu, J, H (2007) Lighting the torch of human rights: the Olympic Games as a vehicle for human rights reform, Northwestern Journal of International Human Rights, 5(2): 214-235 
Mahoney, J, Ntoumanis, N, Mallett, C, and Gucciardi, D. (2014) The motivational antecedents of the development of mental toughness: a self-determination theory perspective. International Review of Sport and Exercise Psychology 7(1): 184-197

Mann, J, Gostin, L, Gruskin, S, Brennan, T, Lazzarini, Z, and Fineberg, H. (1994) Health and Human Rights. Health and Human Rights, 1(1), 6-23. doi:10.2307/4065260

Meggyesy, D (2005[1970]). Out of Their League. Lincoln, Nebraska, Bison Books

Nussbaum, MC. (1988) Nature, function and capability: Aristotle on political distribution in Julia Annas and Grimm RH (eds.), Oxford Studies in Ancient Philosophy: Supplementary Volume, Oxford, Clarendon Press: pp.145-184

Nussbaum, MC (1997) Capabilities and human rights, Fordham Law Review, 66(2): 273-300

Nussbaum, MC (2003) Capabilities as fundamental entitlements: Sen and social justice, Feminist Economics, 9(2-3): 33-59 doi.org/10.1080/1354570022000077926

Nussbaum, MC (2007) Frontiers of justice: Disability, nationality, species membership, Belknap Press, Massachusetts

Nussbaum, MC (2011) Creating capabilities, Cambridge, MA, Harvard University Press

Oakley, B and Green M (2001) The production of Olympic champions: International perspectives on elite sport development system. European Journal for Sport Management, 8, 83-105.

Oliver, J and Lloyd, R (2015) Physical training as a potential form of abuse. In. M. Lang, and M. Hartill (Eds.), Safeguarding, Child Protection and Abuse in Sport (pp. 163-171), London, Routledge

Piekarz, M, and Adams, A (2015) Sport events and human rights: positive promotion or negative erosion? Journal of Policy Research in Tourism, Leisure and Events, 7(3): 220-236

Riessman, C.K., 2008. Narrative methods for the human sciences. London: SAGE

Roan, D (2017) Dan Roan asks whether welfare should come before winning, London, BBC, available at www.bbc.co.uk/sport/cycling/38833749

Robeyns, I (2003) The capability approach: A theoretical survey. Journal of Human Development 6(1): 93-117

Rowe, N (2005) Keynote Paper: How many people participate in sport? The politics, practice and realities of measurement - the English experience. International Association for Sports Information, Beijing Sport University.

Sen, A (1985) Commodities and Capabilities, Amsterdam, North Holland

Sen, A (1985) Well-being, agency and freedom: The Dewey lectures 1984, Journal of Philosophy, 82(4): 169-221

Sen, A (1990) Justice: means versus freedoms, Philosophy and Public Affairs, 19: 111-121

Sen, A (1991) Welfare, preference and freedom, Journal of Econometrics. 50: 15-29

Sen, A (1992) Inequality re-examined, Oxford, Oxford University Press 
Sen, A (1993) Capability and well-being, in M. Nussbaum and Sen, A (Eds) The quality of life, Oxford, Clarendon Press

Sen, A (1995) Gender inequality and theories of justice, in M. Nussbaum and Glover, J (Eds) Women, Culture and Development, 259-73, Oxford, Clarendon Press

Sen, A (1999) Development as freedom, New York, Knopf

Sen, A (2002) Rationality and Freedom. Harvard University Press, Cambridge, Mass

Sen, A (2004) Elements of a theory of human rights. Philosophy and Public Affairs, 32(4): 315-356

Sen, A (2005) Human rights and capabilities, Journal of Human Development, 6(2): 151-166

Shogan, D (1999) The making of high performance athletes: Discipline, diversity and ethics. Toronto: University Toronto Press.

Smith, B, and Sparkes, A, C. (2002) Sport, spinal cord injury, embodied masculinities, and the dilemmas of narrative identity. Men and Masculinities, 4(3): 258-285.

Stake, R. (1994). Case studies. In Denzin N. K and Y. S. Lincoln (Eds.), Handbook of Qualitative Research. (pp. 236-247) Thousand Oaks, CA: Sage Publications.

Stirling, A. E, (2013) Understanding the use of emotionally abusive coaching practices. International Journal of Sports Science and Coaching, 8(4): 625-639.

Stirling, A. E, and Kerr, G. A, (2013) The perceived effects of elite athletes' experiences of emotional abuse in the coach-athlete relationship. International Journal of Sport and Exercise Psychology, 11 (1), 87-100.

Sugden, R. (1993) Welfare, resources and capabilities: A review of Inequality Reexamined by Amartya Sen, Journal of Economic Literature, 31: 1947-1962

Van Manen, M (1990) Researching lived experience: Human science for an action sensitive pedagogy, Albany, State University of New York PressWorld Players Association (2017) Universal Declaration of Player Rights, Washington DC, World Players Association 
Table 1. The Capability approach: key concepts

\begin{tabular}{|c|c|c|c|}
\hline & Key idea & Application & Human rights relevance \\
\hline Functionings & $\begin{array}{l}\text { An achievement one } \\
\text { can make }\end{array}$ & $\begin{array}{l}\text { Specific aspirations and } \\
\text { activities valued within } \\
\text { particular societal } \\
\text { norms }\end{array}$ & $\begin{array}{l}\text { The freedom to do: } \\
\text { meeting individual } \\
\text { aspirations enables one } \\
\text { to achieve wellbeing }\end{array}$ \\
\hline Capabilities & $\begin{array}{l}\text { The ability one has to } \\
\text { make an achievement }\end{array}$ & $\begin{array}{l}\text { The ability to lubricate } \\
\text { desire into action. } \\
\text { Capability } \\
\text { encompasses the } \\
\text { process of converting a } \\
\text { resource into an } \\
\text { achievement - } \\
\text { 'conversion factors' }\end{array}$ & $\begin{array}{l}\text { Having a capability can } \\
\text { enable an individual to } \\
\text { meet desired } \\
\text { functionings. Having the } \\
\text { means and being able to } \\
\text { freely use them }\end{array}$ \\
\hline Freedom & $\begin{array}{l}\text { Not just being free to } \\
\text { choose, but having } \\
\text { freedom of choices } \\
\text { from which one can } \\
\text { then choose - } \\
\text { underpins individual } \\
\text { wellbeing }\end{array}$ & $\begin{array}{l}\text { Freedom has to be } \\
\text { meaningful as only then } \\
\text { is it facilitative in } \\
\text { transforming capability } \\
\text { to functionings }\end{array}$ & $\begin{array}{l}\text { The cornerstone of } \\
\text { human rights theory and } \\
\text { underpins universalistic } \\
\text { ideas of what and how } \\
\text { human rights can be } \\
\text { understood }\end{array}$ \\
\hline Agency & $\begin{array}{l}\text { The ability for an } \\
\text { individual to make } \\
\text { realistic and freely- } \\
\text { chosen life choices }\end{array}$ & $\begin{array}{l}\text { Enables an } \\
\text { examination of } \\
\text { 'unfreedoms' (Sen, } \\
\text { 1999, 3). Enables } \\
\text { identification of } \\
\text { meaningful individual } \\
\text { choice }\end{array}$ & $\begin{array}{l}\text { Allows for consideration } \\
\text { of individual } \\
\text { circumstances and } \\
\text { societal contexts in } \\
\text { understanding whether } \\
\text { an individual can actually } \\
\text { make a choice in a given } \\
\text { situation }\end{array}$ \\
\hline
\end{tabular}

Table 2: Athlete Participant Background

\begin{tabular}{ll}
\hline Adam & Adam is 25 years old and was "hooked on sport" from a young age \\
& competing in "traditional" sports from "as early as he can remember". His \\
father was a significant role model and used to take him along to the local \\
sports club to spend quality time together. After sustaining several serious \\
injuries the chance to gain a professional contract within his sport seemed to \\
be slipping away, so the opportunity for an Olympic talent transfer \\
programme came along at a critical time in his athletic career. Successfully \\
making it through the selection process he dropped out of University and \\
trained for 4 years to make it to an Olympic Games. Currently he is unable to \\
play his sport as a result of a serious injury sustained whilst competing. \\
\hline James is 23 years old and was introduced to his sport at the age of 14 \\
during a school physical education lesson. Within a year he had his first \\
"call up to England" and from that point played at the top level in both junior \\
and senior competitions. When he was 18 years old he got selected to \\
represent Great Britain and at that stage, started full time training. He \\
suspended his University studies in order to concentrate on training as a full- \\
time athlete and take a contract abroad in the run up to an Olympic Games. \\
He is proud of his achievements as an athlete and believes that many of his \\
experiences have shaped him as a person. \\
Ella is 35 years old and came into her sport later in life through an \\
introduction to it at University. Within a year of starting the sport she was \\
competing for English Universities and gained selection at the top club level. \\
On completion of University Ella was balancing the commitment of her sport \\
\hline Ella
\end{tabular}


with a new and demanding career and at this time she gained her first call up to the England senior squad. She achieved her first cap after a successful European development tournament and decided to commit more to the sport in the lead up to a major international competition. Ella's international career was marred by negative experiences that led to her retirement from international sport. 